\title{
Effects of Atorvastatin on the Pharmacokinetics of Nicardipine after Oral and Intravenous Administration in Rats
}

\author{
Jun-Shik $\mathrm{CHOI}^{1}$, Sung-II $\mathrm{HA}^{2}$, and Dong-Hyun $\mathrm{CHOI}^{2, *}$ \\ ${ }^{1}$ Pharmaceutic Division, College of Pharmacy , ${ }^{2}$ Cardiovascular Division, College of Medicine, Chosun University, \\ Gwangju 501-759, Republic of Korea
}

(Received March 13, 2010; Revised April 17, 2010; Accepted April 19, 2010)

\begin{abstract}
The aim of this study was to investigate the effect of atrovasatatin on the pharmacokinetics of nicardipine after oral and intravenous administration of nicardipine to rats. Nicardipine was administered orally $(12 \mathrm{mg} / \mathrm{kg}$ ) or intravenously (i.v., $4 \mathrm{mg} / \mathrm{kg}$ ) without or with oral administration of atrovasatatin $(0.3$ or 1.0 $\mathrm{mg} / \mathrm{kg}$ ) to rats. The effect of atorvastatin on the P-glycoprotein (P-gp) as well as CYP3A4 activity was also evaluated. Atorvastatin inhibited CYP3A4 enzyme activity in a concentration-dependent manner with $50 \%$ inhibition concentration $\left(\mathrm{IC}_{50}\right)$ of $48 \mu \mathrm{M}$. Compared to the controls (nicardipine alone), the area under the plasma concentration-time curve (AUC) of nicardipine was significantly $(1.0 \mathrm{mg} / \mathrm{kg}, p<0.05)$ greater by $16.8-45.4 \%$, and the peak plasma concentration $\left(C_{\max }\right)$ was significantly $(1.0 \mathrm{mg} / \mathrm{kg}, p<0.05)$ higher by $28.0 \%$ after oral administration of nicardipine with atorvastatin, respectively. Consequently, the relative bioavailability (R.B.) of nicardipine was increased by 1.17 - to 1.45 -fold and the absolute bioavailability (A.B.) of nicardipine with atrovasatatin was significantly greater by $16.7-20.9 \%$ compared to that of the controls (14.3\%). Compared to the i.v. control, atrovasatatin did not significantly change pharmacokinetic parameters of i.v. administration nicardipine. The enhanced oral bioavailability of nicardipine by atorvastatin suggests that CYP3A subfamily-mediated metabolism were inhibited in the intestine and/or in the liver rather than P-gp-mediated efflux of nicardipine. Based on these results, modification of nicardipine of dosage regimen is required in the patients. Human studies are required to prove the above hypothesis.
\end{abstract}

Keywords: Nicardipine, Atrovasatatin, Bioavailability, Pharmacokinetics, CYP3A subfamily, P-gp, Rats

\section{INTRODUCTION}

Nicardipine, a dihydropyridine calcium channel antagonist, causes coronary and peripheral vasodilatation by blocking the influx of extracellular calcium across cell membranes. Nicardipine is arterioselective and effective for the treatment of hypertension, myocardial ischemia, and vasospasm in surgical patients (Kishi et al., 1984; Hysing et al., 1986). Nicardipine has also been used experimentally as a probe to study the effects of calcium channel antagonists on the role of sympathetic nervous system activity in the development of cardiovascular risk (Van Swieten et al., 1997). The pharmacokinetic parameters of nicardipine are non-linear due to hepatic first-pass metabolism, thus, the extent of oral bioavailability $(F)$ was

${ }^{*}$ Corresponding author

Tel: +82-62-220-3773 Fax: +82-62-222-3858

E-mail: dhchoi@chosun.ac.kr low about $35 \%$ following a $30 \mathrm{mg}$ dose at steady state (Graham et al., 1984; Graham et al., 1985). It is a substrate of cytochrome P450 (CYP) 3A subfamily, especially CYP3A4 in humans and forms to pharmacologically inactive metabolite (Higuchi and Shiobara, 1980; Guengerich et al., 1986; Guengerich, 1991). In addition, nicardipine is also a P-glycoprotein (P-gp) substrate (Hu et al., 1996; Wang et al., 2000).

Atorvastatin, a 3-hydroxy-3-methylglutaryl-coenzyme A (HMG-CoA) reductase inhibitor, is widely used to prevent the progression of atherosclerosis by lowering plasma low-density lipid (LDL) levels in patients with hypercholesterolemia (Doppenschmitt et al., 1999). Atorvastatin has been identified as a substrate of CYP3A4 which could be controlling factors for the low systemic availability of atorvastatin (Lea and McTavish, 1997). Accordingly, previous studies have revealed that many CYP3A4 inhibitors including itraconazole, clarithromycin, azithromycin, nelfinavir 
and grapefruit juice increased the bioavailability of atorvastatin (Lennernas, 2003). Holtzman et al. (2006) reported that HMG-CoA reductase inhibitors (statins) are inhibitors of P-gp in the rodent system, but the effects of atorvastatin on the inhibition of CYP3A4 and P-gp activity are partially ambiguous. Thus we attempted to re-evaluate CYP3A4 and P-gp activity using rhodamine-123 retention assay in P-gp-overexpressed MCF-7/ADR cells. This may be explained in part by the difference in the transport mechanisms of hydrophilic and lipophilic statins. For atorvastatin, a hydrophilic statin, specific transporter(s) including OATP1B1 are involved in its hepatic uptake (Shitara and Sugiyama, 2006) and thus the change of the metabolic rate itself may not drastically alter the pharmacokinetics of atorvastatin while it makes a greater alteration in those of simvastatin and lovastatin whose membrane transports are mainly mediated by passive diffusion (Lennernas, 2003). Antihypertensive agents are commonly co-administered with cholesterol-lowering agents in clinics. There are some reports on the effects of calcium channel antagonists on the pharmacokinetics of HMG-CoA reductase inhibitors. Calcium-channel blockers increased plasma concentrations of some statins (lovastatin, pravastatin and simvastatin), possibly through the inhibition of CYP 3A4 and P-gp (Azie et al., 1998; Mousa et al., 2000). But there are fewer reports about the effects of HMG-CoA reductase inhibitors on the bioavailability or pharmacokinetics of calcium channel antagonists in rats (Choi et al., 2006; Choi et al., 2008). Moreover, atorvastatin and nicardipine could be prescribed for the prevention or treatment of cardiovascular diseases as a combination therapy.

The low bioavailability of oral nicardipine is mainly due to pre-systemic metabolism by CYP3A4 and P-gp mediated efflux in the intestine. Therefore, the present study aimed to investigate the effect of atorvastatin on the intravenous and oral pharmacokinetics of nicardipine in rats.

\section{MATERIALS AND METHODS}

\section{Chemicals and apparatus}

Nicardipine, atrovasatatin and nimodipine [internal standard for high-performance liquid chromatograph (HPLC) analysis of nicardipine] were purchased from SigmaAldrich Co. (St. Louis, MO, USA). HPLC grade acetonitrile was a product from Merck Co. (Darmstadt, Germany). Other chemicals for this study were of reagent grade.

HPLC system used in this study were a Waters 1515 isocratic HPLC pump, a Waters 717 plus autosampler and a Waters ${ }^{\mathrm{TM}} 474$ scanning fluorescence detector (Waters Co., Milford, MA, USA), a HPLC column temperature con- troller (Phenomenex Inc., CA, USA), a Bransonic ${ }^{\circledR}$ Ultrasonic Cleaner (Branson Ultrasonic Co., Danbury, CT, USA), a vortex-mixer (Scientific Industries Co., NY, USA) and a high-speed micro centrifuge (Hitachi Co., Tokyo, Japan).

\section{Animal experiments}

Male Sprague-Dawley rats of 7-8 weeks of age (weighing 270-300 g) were purchased from Dae Han Laboratory Animal Research Co. (Choongbuk, Republic of Korea) and given free access to a commercial rat chow diet (No. 322-7-1; Superfeed Co., Gangwon, Republic of Korea) and tap water ad libitum. The animals were housed (two rats per cage) in a clean-room maintained at a temperature of $22 \pm 2^{\circ} \mathrm{C}$ and relative humidity of $50-60 \%$, with 12-h light and dark cycles. The rats were acclimated under these conditions for at least 1 week. All animal studies were performed in accordance with the "Guiding Principles in the Use of Animals in Toxicology" adopted by the Society of Toxicology (USA) and the Animal Care Committee of Chosun University (Gwangju, Republic of Korea) approved the protocol of this animal study. The rats were fasted for at least 24-h prior to beginning the experiments and had free access to tap water. Each animal was anaesthetized with light ether. The left femoral artery and vein were cannulated using polyethylene tubing (SP45, I.D. $0.58 \mathrm{~mm}$, O.D. $0.96 \mathrm{~mm}$; Natsume Seisakusho Co. LTD., Tokyo, Japan) for blood sampling and drug administration, respectively.

\section{Oral and intravenous administration of nicardipine}

The rats were randomly divided into four groups $(n=6$, each); an oral group (12 mg/kg of nicardipine dissolved in water; homogenized at $36^{\circ} \mathrm{C}$ for $30 \mathrm{~min} ; 3.0 \mathrm{ml} / \mathrm{kg}$ ) without (control) or with 0.3 or $1.0 \mathrm{mg} / \mathrm{kg}$ of oral atrovasatatin, and an i.v. group (4 mg/ $\mathrm{kg}$ of nicardipine, dissolved in $0.9 \%$ $\mathrm{NaCl}$-injectable solution; homogenized at $36^{\circ} \mathrm{C}$ for $30 \mathrm{~min}$; $1.5 \mathrm{ml} / \mathrm{kg}$ ) without (control) or with 0.3 or $1.0 \mathrm{mg} / \mathrm{kg}$ of oral atrovasatatin. Nicardipine was administered orally using a gastric gavage tube, and atrovasatatin was orally administered $30 \mathrm{~min}$ prior to oral or intravenous administration of nicardipine. Nicardipine for i.v. administration was injected through the femoral vein within $0.5 \mathrm{~min}$. A blood sample $(0.45 \mathrm{ml})$ was collected into heparinized tubes from the femoral artery at 0 (control), 0.017 (end of the infusion), $0.1,0.25,0.5,1,2,3,4,8,12$ and $24 \mathrm{~h}$ after intravenous infusion, and $0.1,0.25,0.5,1,2,3,6,8,12$ and $24 \mathrm{~h}$ after oral administration. The blood samples were centrifuged (13,000 rpm, $5 \mathrm{~min}$ ), and the plasma samples were stored at $-40^{\circ} \mathrm{C}$ until HPLC analysis of nicardipine. An approximately $1 \mathrm{ml}$ of whole blood collected from un- 
treated rats was infused via the femoral artery at 0.25, 1, 3 and $8 \mathrm{~h}$, respectively, to replace the blood loss due to blood sampling.

\section{HPLC assay}

The plasma concentrations of nicardipine were determined by a HPLC assay method reported by Eastwood et al. (1990). Briefly, a 50- $\mu$ l aliquot of nimodipine $(2 \mu \mathrm{g} /$ $\mathrm{ml})$, a $20-\mu \mathrm{l}$ aliquot of $2 \mathrm{~N}$ sodium hydroxide solution and 1.2-ml of tert-butylmethylether:hexane (75:25) were added to $0.2-\mathrm{ml}$ aliquot of plasma sample. The mixture was then stirred for $2 \mathrm{~min}$ and centrifuged (13,000 rpm, $10 \mathrm{~min}$ ). A $1.0 \mathrm{ml}$ aliquot of the organic layer was transferred to a clean test tube and evaporated under a gentle stream of nitrogen at $35^{\circ} \mathrm{C}$. The residue was dissolved in $200-\mu \mathrm{l}$ of the mobile phase and centrifuged (13,000 rpm, $5 \mathrm{~min}$ ). A $50-\mu$ l aliquot of the supernatant was injected into the HPLC system. Chromatographic separations were achieved using a Symmetry ${ }^{\circledR} C_{18}$ column $(4.6 \times 150 \mathrm{~mm}, 5 \mu \mathrm{m}$, Waters), and a $\mu$ Bondapak ${ }^{\mathrm{TM}} \mathrm{C}_{18}$ HPLC Precolumn $(10 \mu$ $\mathrm{m}$, Waters). The mobile phase was acetonitrile:0.015 M $\mathrm{KH}_{2} \mathrm{PO}_{4}(60: 40, \mathrm{v} / \mathrm{v}, \mathrm{pH} 4.5)$ with $2.8 \mathrm{mM}$ triethylamine, which was run at a flow rate of $1.5 \mathrm{ml} / \mathrm{min}$. Chromatography was performed at a temperature of $30^{\circ} \mathrm{C}$ that was set by a HPLC column temperature controller. The UV detector was set to $254 \mathrm{~nm}$. The retention times of nicardipine and the internal standard were 7.8 and $4.2 \mathrm{~min}$, respectively. The detection limit of nicardipine in rat's plasma was $5 \mathrm{ng} / \mathrm{ml}$. The coefficients of variation for nicardipine were below $14.1 \%$.

\section{CYP inhibition assay}

The inhibition assays of human CYP3A4 enzyme activity were performed in a multiwell plate using the CYP inhibition assay kit (BD Bioscience, San Jose, CA). Briefly, human CYP enzymes were obtained from baculovirus-infected insect cells. CYP3A4 substrate (7-Benzyloxy-4(trifluoromethyl)couamrin (BFC)) was incubated with or without test compounds in a reaction mixture containing 1 pmol of CYP3A4 enzyme and the NADPH-generating system (1.3 mM NADP, $3.54 \mathrm{mM}$ glucose 6-phosphate, 0.4 $\mathrm{U} / \mathrm{ml}$ glucose 6-phosphate dehydrogenase and $3.3 \mathrm{mM}$ $\mathrm{MgCl}_{2}$ ) in potassium phosphate buffer ( $\left.\mathrm{pH} 7.4\right)$. Reactions were terminated by adding stop solution after $45 \mathrm{~min}$. Metabolite concentrations were measured with a spectrofluorometer (Molecular Device, Sunnyvale, CA) set at an excitation wavelength of $409 \mathrm{~nm}$ and an emission wavelength of $530 \mathrm{~nm}$. Positive control ( $1 \mu \mathrm{M}$ ketoconazole) was run on the same plate and produced $99 \%$ inhibition. All experiments were performed in duplicate, and the re- sults are expressed as the percent of inhibition.

\section{Rhodamine-123 retention assay}

The P-gp-overexpressed multidrug resistant human breast carcinoma cell line (MCF-7/ADR cells) was seeded in 24-well plates. At $80 \%$ confluence, the cells were incubated in fetal bovine serum (FBS)-free Dulbecco's modified Eagle's medium (DMEM) for $18 \mathrm{~h}$. The culture medium was changed with Hanks' balanced salt solution and the cells were incubated at $37^{\circ} \mathrm{C}$ for $30 \mathrm{~min}$. After incubation of the cells with $20-\mu \mathrm{M}$ rhodamine-123 in the presence or absence of atorvastatin $(1,3$ or $10 \mu \mathrm{M})$ or verapamil $(100 \mu \mathrm{M})$ for $90 \mathrm{~min}$, the medium was completely aspirated. The cells were then washed three times with an ice-cold phosphate buffer $(\mathrm{pH} \mathrm{7.0)}$ and lysed in lysis buffer. The rhodamine-123 fluorescence in the cell lysates was measured using excitation and emission wavelengths of 480 and 540 $\mathrm{nm}$, respectively. Fluorescence values were normalized to the total protein content of each sample and presented as the percentage ratio to control.

\section{Pharmacokinetic analysis}

The pharmacokinetic parameters were calculated using a non-compartmental analysis (WinNonlin; software version 4.1; Pharsight Co., Mountain View, CA, USA). The elimination rate constant $\left(\mathrm{K}_{\mathrm{el}}\right)$ was calculated by log-linear regression of nicardipine concentration data during the elimination phase, and the terminal half-life $\left(t_{1 / 2}\right)$ was calculated by $0.693 / \mathrm{K}_{\mathrm{el}}$. The peak plasma concentration $\left(\mathrm{C}_{\max }\right)$ and time to reach peak plasma concentration $\left(\mathrm{T}_{\max }\right)$ of nicardipine were directly read from the experimental data. The area under the plasma concentration-time curve $\left(\mathrm{AUC}_{0-\mathrm{t}}\right)$ from time zero to the time of last measured concentration $\left(\mathrm{C}_{\text {last }}\right)$ was calculated by the linear trapezoidal rule. The $A \cup C$ zero to infinite $\left(A \cup C_{0-\infty}\right)$ was obtained by the addition of $\mathrm{AUC}_{0-\mathrm{t}}$ and the extrapolated area determined by $\mathrm{C}_{\text {last }} / \mathrm{K}_{\mathrm{el}}$. Total body clearance $(\mathrm{CL})$ was calculated by Dose/AUC. The absolute bioavailability (F.\%) of nicardipine was calculated by $\mathrm{AUC}_{\text {oral }} / \mathrm{AUC}_{\mathrm{iv}} \times \mathrm{Dose}_{\mathrm{i.v}} /$ Dose $_{\text {oral }} \times 100$, and the relative bioavailability (R.B.\%) of nicardipine was estimated by $A \cup C_{\text {with atrovasatatin }} / \mathrm{AUC}_{\text {control }}$ $\times 100$.

\section{Statistical analysis}

All data are expressed with their standard deviation (mean $\pm \mathrm{SD}$ ). Statistical analysis was conducted using a one-way analyses of variance (ANOVA) followed by a posteriori testing with Dunnett's correction. Differences were considered significant at a level of $p<0.05$ 


\section{RESULTS}

\section{Inhibitory effect of atorvastatin on CYP3A4}

The inhibitory effect of atorvastatin on CYP3A4 activity is shown in Fig. 1. Atorvastatin inhibited CYP3A4 enzyme activity in a concentration-dependent manner and the 50 $\%$ inhibition concentration $\left(\mathrm{IC}_{50}\right)$ values of atorvastatin on

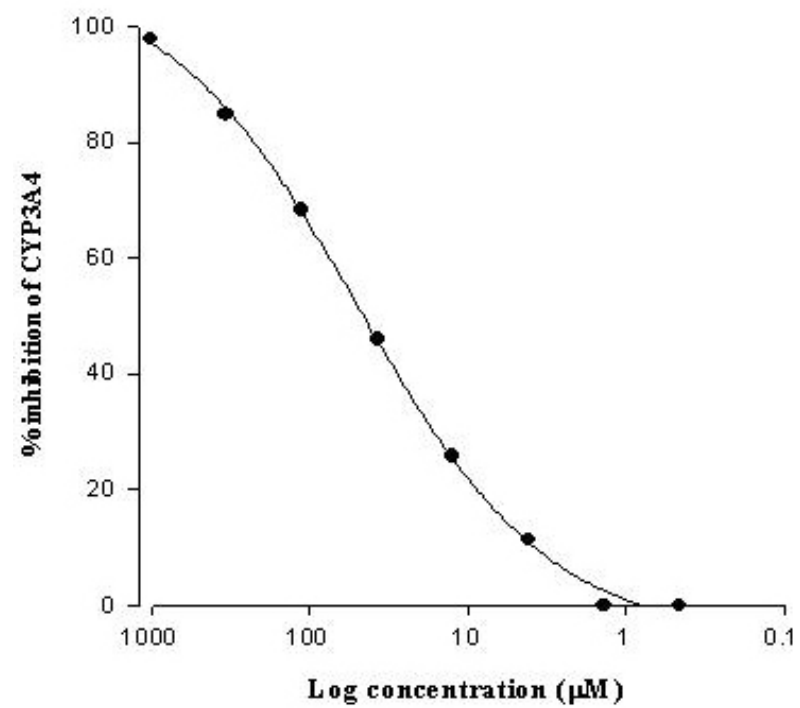

Fig. 1. Inhibitory effect of atorvastatin on CYP3A4 activity. All experiments were performed in duplicate, and results are expressed as the percent of inhibition.

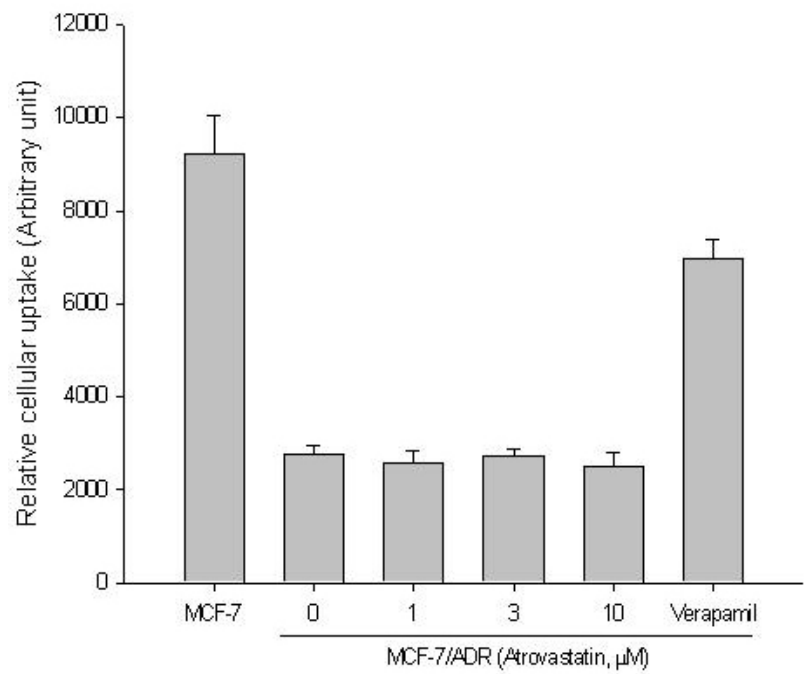

Fig. 2. Rhodamine-123 retention. MCF-7/ADR cells were preincubated with atrovastatin for $30 \mathrm{~min}$, After incubation of MCF-7/ADR cells with $20 \mu \mathrm{M}$ R-123 for $90 \mathrm{~min}$. The values were divided by total protein contents of each sample. Verapamil $(100 \mu \mathrm{M})$ was used as a positive control. Data represents mean \pm SD of 6 separate samples.
CYP3A4 activity was determined as $48 \mu \mathrm{M}$.

\section{Rhodamine-123 retention assay.}

As shown in Fig. 2, accumulation of rhodamine-123, a $\mathrm{P}$-gp substrate, was not reduced in MCF-7/ADR cells overexpressing P-gp compared to that in MCF-7 cells lacking

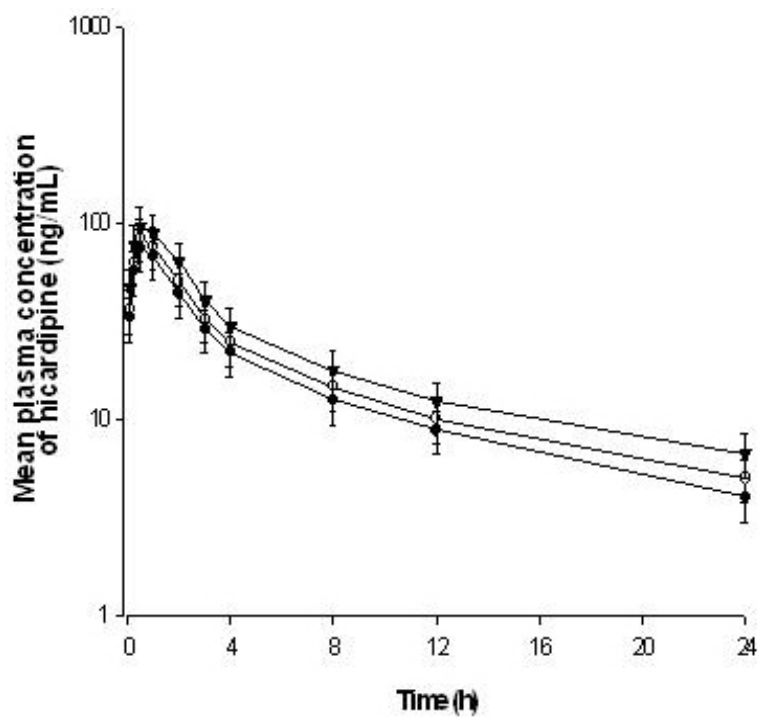

Fig. 3. Mean arterial plasma concentration-time profiles of nicardipine after its oral administration $(12 \mathrm{mg} / \mathrm{kg})$ without $(\mathbf{O})$ or with $0.3 \mathrm{mg} / \mathrm{kg}(\bigcirc)$ and $1.0 \mathrm{mg} / \mathrm{kg}(\boldsymbol{\nabla})$ of atrovasatatin to rats. Bars represent the standard deviation $(n=6)$.

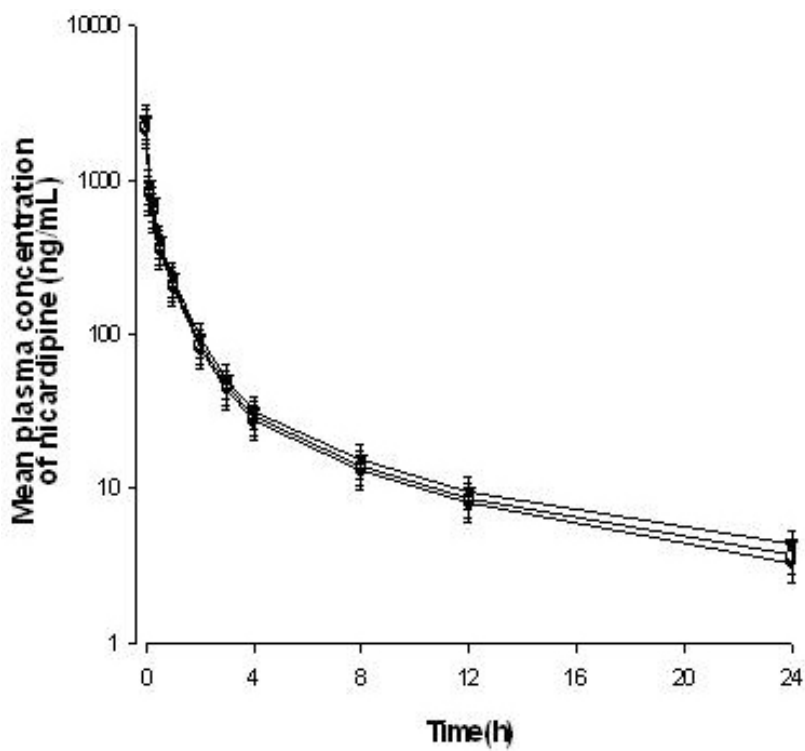

Fig. 4. Mean arterial plasma concentration-time profiles of nicardipine after its i.v. administration $(4 \mathrm{mg} / \mathrm{kg})$ without $(\bullet)$ or with $0.3 \mathrm{mg} / \mathrm{kg}(\bigcirc)$ and $1.0 \mathrm{mg} / \mathrm{kg}(\nabla)$ of atrovasatatin to rats. Bars represent the standard deviation $(n=6)$. 
P-gp. This result suggests that atorvastatin did not significantly inhibit P-gp activity.

\section{Effect of atorvastatin on the pharmacokinetics of nicar- dipine.}

The mean arterial plasma concentration-time profiles of oral nicardipine with or without atrovasatatin are shown in Fig. 3 and 4. The relevant pharmacokinetic parameters of nicardipine are also listed in Table I and II.

The area under the plasma concentration-time curve (AUC) was significantly $(1.0 \mathrm{mg} / \mathrm{kg}, p<0.05)$ greater by $16.8-45.4 \%$, and the peak concentration $\left(\mathrm{C}_{\max }\right)$ was significantly $(1.0 \mathrm{mg} / \mathrm{kg}, p<0.05)$ higher by $28.0 \%$ with atrovasatatin after oral administration of nicardipine. Consequently, the relative bioavailability (R.B.) of nicardipine was increased by 1.17 - to 1.45 -fold, and the absolute bioavailability $(F)$ of nicardipine with atrovasatatin was significantly $(1.0 \mathrm{mg} / \mathrm{kg}, p<0.05)$ increased by $16.7-20.9 \%$, compared to that of the controls $(14.3 \%)$. There was no significant change in the time to reach peak concentration $\left(T_{\max }\right)$ and the half-life $\left(\mathrm{t}_{1 / 2}\right)$ of nicardipine with atrovasatatin.

Table I. Mean ( \pm SD) pharmacokinetic parameters of nicardipine after its oral administration $(12 \mathrm{mg} / \mathrm{kg}$ ) with or without atrovasatatin to rats

\begin{tabular}{lccc}
\hline \multirow{2}{*}{ Paramater } & $\begin{array}{c}\text { Control without } \\
\text { atorvastatin }\end{array}$ & \multicolumn{2}{c}{ Nicardipine + atrovasatatin } \\
\cline { 3 - 4 } & & $0.3 \mathrm{mg} / \mathrm{kg}$ & $1.0 \mathrm{mg} / \mathrm{kg}$ \\
\hline $\mathrm{AUC}(\mathrm{ng} \cdot \mathrm{h} / \mathrm{ml})$ & $416 \pm 86$ & $486 \pm 108$ & $605 \pm 148^{\mathrm{a}}$ \\
$\mathrm{C}_{\max }(\mathrm{ng} / \mathrm{ml})$ & $75 \pm 18$ & $84 \pm 21$ & $96 \pm 23^{\mathrm{a}}$ \\
$\mathrm{T}_{\max }(\mathrm{h})$ & $0.46 \pm 10$ & $0.46 \pm 0.10$ & $0.58 \pm 0.20$ \\
$\mathrm{t}_{1 / 2}(\mathrm{~h})$ & $8.5 \pm 1.7$ & $9.1 \pm 1.9$ & $9.9 \pm 2.4$ \\
A.B. $(\%)$ & $14.3 \pm 3.0$ & $16.7 \pm 3.1$ & $20.9 \pm 4.2^{\mathrm{a}}$ \\
R.B. $(\%)$ & 100 & 117 & 145 \\
\hline
\end{tabular}

Mean \pm SD $(n=6),{ }^{a} p<0.05$, significant difference compared to controls, AUC: area under the plasma concentration-time curve from $0 \mathrm{~h}$ to time infinity, $\mathrm{C}_{\max }$ : peak plasma concentration, $\mathrm{T}_{\max }$ : time to reach peak concentration, $t_{1 / 2}$ : terminal half-life, A.B. (\%): absolute bioavailability, R.B. (\%): relative bioavailability.

Table II. Mean ( \pm SD) pharmacokinetic parameters of nicardipine after its intravenous administration $(4 \mathrm{mg} / \mathrm{kg})$ with or without atrovasatatin to rats (Mean \pm SD) $(n=6)$

\begin{tabular}{lccc}
\hline \multirow{2}{*}{ Paramater } & $\begin{array}{c}\text { Control without } \\
\text { atorvastatin }\end{array}$ & \multicolumn{2}{c}{ Nicardipine + atrovasatatin } \\
\cline { 3 - 4 } & $0.3 \mathrm{mg} / \mathrm{kg}$ & $1.0 \mathrm{mg} / \mathrm{kg}$ \\
\hline $\mathrm{AUC}(\mathrm{ng} \cdot \mathrm{h} / \mathrm{ml})$ & $969 \pm 204$ & $1,044 \pm 226$ & $1,138 \pm 259$ \\
$\mathrm{CL}(\mathrm{ml} / \mathrm{min} / \mathrm{kg})$ & $51.6 \pm 12.5$ & $47.9 \pm 10.4$ & $43.9 \pm 9.3$ \\
$\mathrm{t}_{1 / 2}(\mathrm{~h})$ & $6.9 \pm 1.4$ & $7.1 \pm 1.6$ & $7.4 \pm 1.8$ \\
\hline
\end{tabular}

AUC: area under the plasma concentration-time curve from time 0 to infinity, $\mathrm{CL}$ : total body clearance, $\mathrm{t}_{1 / 2}$ : terminal half-life.
The mean arterial plasma concentration-time profiles of i.v. nicardipine $(4 \mathrm{mg} / \mathrm{kg})$ with or without atrovasatatin $(0.3$ or $1.0 \mathrm{mg} / \mathrm{kg}$ ) are shown in Fig. 4. The relevant pharmacokinetic parameters of nicardipine are listed in Table II. Atrovasatatin did not significantly change pharmacokinetic parameters of i.v. administration of nicardipine, suggesting that the metabolism of nicardipine by atorvastatin via hepatic CYP3A subfamily and renal excretion were almost negligible after intravenous administration in rats. Thus, enhanced oral bioavailability of nicardipine was due to increasing the intestinal absorption or reducing gut wall metabolism.

\section{DISCUSSION}

CYPs enzymes make a contribution significantly to the "first-pass" metabolism and oral bioavailability of many drugs. The "first-pass" metabolism of compounds in the intestine limits absorption of toxic xenobiotics and may ameliorate side effects. Moreover, induction or inhibition of intestinal CYPs may be responsible for significant drug and drug interactions when one agent decreases or increases the bioavailability and absorption rat constant of a concurrently administered drug (Kaminsky and Fasco, 1991).

Based on the broad overlap in the substrate specificities as well as co-localization in the small intestine, the primary site of absorption for orally administered drugs, CYP3A4 and P-gp have been recognized as a concerted barrier to the drug absorption (Cummins et al., 2002; Benet et al., 2003). Therefore, dual inhibitors against both CYP3A4 and $\mathrm{P}$-gp should have a great impact on the bioavailability of many drugs where CYP3A4 metabolism as well as P-gp mediated efflux is the major barrier to the systemic availability and so could act synergistically to limit oral bioavailability of its substates (Saeki et al., 1993; Wacher et al., 2001).

Studies on drug interactions with grapefruit juice have provided much understanding of the role of intestinal CYP450 in the absorption of orally administered drugs. CYP3A4 is the predominant P450 present in the small intestine (Kolars et al., 1992). The inhibitory effect of atorvastatin on CYP3A4 activity is shown in Fig. 1. Atorvastatin inhibited CYP3A4 enzyme activity in a concentration-dependent manner and the $50 \%$ inhibition concentration $\left(\mathrm{IC}_{50}\right)$ values of atorvastatin on CYP3A4 activity was determined as $48 \mu \mathrm{M}$. These results are consistent with the report (Lea and McTavish, 1997).

A cell-based P-gp activity test using rhodamine-123 also showed that atorvastatin did not significantly inhibite P-gp activity (Fig. 2). These results are not consistent with the 
report (Holtzman et al., 2006). The area under the plasma concentration-time curve (AUC) was significantly greater by $16.8-45.4 \%$, and the peak concentration $\left(\mathrm{C}_{\max }\right)$ was significantly higher by $28.0 \%$ with atrovasatatin after oral administration of nicardipine. The absolute bioavailability $(F)$ of nicardipine with atrovasatatin was significantly increased by $16.7-20.9 \%$, compared to that of the controls $(14.3 \%)$.

Orally administered nicardipine is a substrate for CYP3A-mediated metabolism. The enhanced oral bioavailability of nicardipine by atorvastatin could be mainly due to inhition of CYP3A subfamily in the intestine and/or in the liver rather than P-gp efflux in the intestine. Atrovasatatin did not significantly change pharmacokinetic parameters of i.v. nicardipine, suggesting that atorvastatin did not inhibit the metabolism of nicardipine via hepatic CYP3A subfamily and renal excetion in rats. This result appeared to be consistent with a previous report that oral administration of atrovasatatin significantly increased the oral bioavailability of verapamil in rats (Choi et al., 2008).

The increased in bioavailability of orally administered nicardipine by atorvastatin might be due to inhibition of CYP3A subfamily rather than P-gp in the intestine, since the metabolism of nicardipine by atorvastatin via hepatic CYP3A subfamily and renal excretion were almost negligible after intravenous administration. These results suggest enhanced bioavailability of nicardipine may be mainly inhibited CYP3A metabolism in the intestine and /or in the liver by atrovasatatin.

\section{CONCLUSION}

While there was no significant effect on the i.v. pharmacokinetics of nicardipine, atrovasatatin significantly enhanced the oral bioavailability of nicardipine. Therefore, concomitant use of oral nicardipine and atrovasatatin will require close monitoring for potential drug interactions.

\section{REFERENCES}

Azie, N. E., Brater, D. C., Becker, P. A., Jones, D. R. and Hall, S. D. (1998). The interaction of diltiazem with lovastatin and pravastatin. Clin. Pharmacol. Ther. 64, 369-377.

Benet, L. Z., Cummins, C. L. and Wu, C. Y. (2003). Transporter-enzyme interactions: implications for predicting drugdrug interactions from in vitro data. Curr. Drug Metab. 4, 393-398.

Choi, D. H., Chang, K. S., Hong, S. P. and Choi, J. S. (2008). Effect of atrovastatin on intravenous and oral pharmacokinetics of verapamil in rats. Biopharm. Drug Dispos. 29, 45-50.

Choi, J. S., Piao, Y. J. and Han, H. K. (2006). Phatmacokinetics interaction between fluvastatin and diltiazem in rats. Biopharm. Drug Dispos. 27, 437-441.

Cummins, C. L., Jacobsen, W. and Benet, L. Z. (2002). Unmasking the dynamic interplay between intestinal P-glycoprotein and CYP3A4. J. Pharmacol. Exp. Ther. 300, 10361045.

Doppenschmitt, S., Spahn-Langguth, H., Rerardh, C. G. and Langguth, P. (1999). Role of P-glycoprotein-mediated secretion in aborptive drug permeability: an approach using passive membrane permeability and affinity to P-glycoprotein. J. Pharm. Sci. 88, 1067-1072.

Eastwood, R. J., Galustian, C., Bhamra, R. K. and Holt, D. W. (1990). High-performance liquid chromatographic method for the measurement of nicardipine in plasma or serum. $J$. Chromatogr. 530, 463-468.

Graham, D. J., Dow, R. J., Freedman, D., Mroszczak, E. and Ling, T. (1984). Pharmacokinetics of nicardipine following oral and intravenous administration in man. Postgrad. Med. J. 4, 7-10.

Graham, D. J., Dow, R. J., Hall, D. J., Alexander, O. F., Mroszczak, E. J. and Freedman, D. (1985). The metabolism and pharmacokinetics of nicardipine hydrochloride in man. Br. J. Cli. Pharmacol. 1, 23-28.

Guengerich, F. P. (1991). Reactions and significance of cytochrome P-450 enzymes. J. Biol. Chem. 266, 10019-10022.

Guengerich, F. P., Martin, M. V., Beaune, P. H., Kre-mers, P., Wolff, T. and Waxman, D. J. (1986). Characterization of rat and human liver microsomal cytochrome P-450 forms involved in nifedipine oxidation, a prototype for genetic polymorphism in oxidative drug metabolism. J. Biol. Chem. 261, 5051-5060.

Higuchi, S. and Shiobara, Y. (1980). Metabolic fate of nicardipine hydrochloride, a new vasodilator, by various species in vitro. Xenobiotica 10, 889-896.

Holtzman, C. W., Wiggins, B. S. and Spinler, S. A. (2006). Role of P-glycoprotein in statin drug interaction. Pharmacotherapy 26, 1601-1607.

Hu, Y. P., Chapey, C. and Robert, J. (1996). Relationship between the inhibition of azidopine binding to P-glycoprotein by MDR modulators and their efficiency in restoring doxorubicin intracellular accumulation. Cancer Lett. 109, 203209.

Hysing, E. S., Chelly, J. E., Doursout, M. F., Hartley, C. and Merin, R. G. (1986). Cardiovascular effects of and interaction between calcium blocking drugs and anesthetics in chronically instrumented dogs. Nicardipine and isoflurane. Anaesthesiology 65, 385-391.

Kaminsky, L. S. and Fasco, M. J. (1991). Small intestinal cytochromes P450. Crit. Rev. Toxicol. 21, 407-422.

Kishi, Y., Okumura, F. and Furuya, H. (1984). Haemodynamic effects of nicardipine hydrochloride. Studies during its use to control acute hypertension in anaesthetized patients. Br. J. Anaesth. 56, 1003-1007.

Kolars, J. C., Schmiedlin-Ren, P., Schuetz, J. D., Fang, C. and Watkins, P. B. (1992). Identification of rifampin-inducible P450IIIA4 (CYP3A4) in human small bowel enterocytes. $J$. Clin. Invest. 90, 1871-1878.

Lea, A. P. and McTavish, D. (1997). Atrovastatin: a review of its pharmacology and therapeutic potential in the management of hyperlipidaemias. Drugs 53, 828-847. 
Lennernas, H. (2003). Clinical pharmacokinetics of atrovastatin. Clin. Pharmacokinet. 42, 1141-1160.

Mousa, O., Brater, D. C., Sunblad, K. J. and Hall, S. D. (2000). The interaction of diltiazem with simvastatin. Clin. Pharmacol. Ther. 67, 267-274.

Saeki, T., Ueda, K., Tanigawara, Y., Hori, R. and Komano, T. (1993). P-glycoprotein-mediated transcellular transport of MDR-reversing agents. FEBS Lett. 324, 99-102.

Shitara, Y. and Sugiyama, Y. (2006). Pharmacokinetics and pharmacodynamic alterations of 3-hydroxy-3-methylglutaryl coenzyme A (HMG-CoA) reductase inhibitors: drug-drug interaction and interindixidual differences in transporter and metabolic enzyme function. Pharmacol. 112, 71-105.

Van Swieten, P. A., Hansson, L. and Epstein, M. (1997). Slowly acting calcium antagonists and their merits. Blood Press 6 78-90.

Wacher, V. J., Salphati, L. and Benet, L. Z. (2001). Active secretion and enterocytic drug metabolism barriers to drug absorption. Adv. Drug Deliv. Rev. 46, 89-102.

Wang, E. J., Casciano, C. N., Clement, R. P. and Johnson, W. W. (2000). Two transport binding sites of P-glycoprotein are unequal yet contingent: initial rate kinetic analysis by ATP hydrolysis demonstrates intersite dependence. Biochim. Biophys. Acta. 1481, 63-74. 